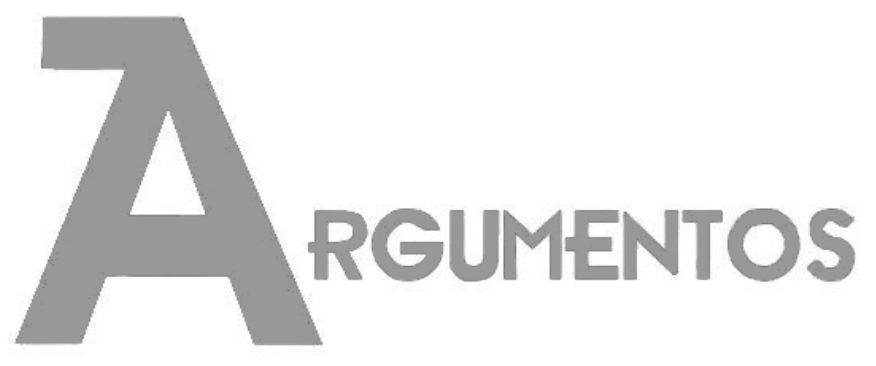

Vol. 18, n. 1, jan./jun. 2021 ISSN: 2527-2551 (online)

https://www.periodicos.unimontes.br/index.php/argumentos

\title{
Participar: verbo em voz altiva - Adolescentes e jovens sujeitos de mudança das suas realidades no Brasil profundo
}

Luciana Pinto ${ }^{1}$

Recebido em: 22/01/2020

Aprovado em: 08/02/2020

Resumo: As juventudes camponesas do Nordeste brasileiro têm múltiplas identidades e anseios. Não é suficiente referenciá-las a partir de seu pertencimento territorial ou somente por questões de gênero ou étnico-raciais. Desconstruções destes imaginários, que também compartimentam as lutas sociais e reforçam estereótipos, são movimentos cotidianos realizados a partir de mecanismos os mais diversos. Desde a experiência aqui apresentada, a partir do cenário de pandemia da Covid-19, o fio condutor para esta reflexão é a dimensão da participação de adolescentes e jovens - meninos, meninas, negros e negras, camponeses estudantes, e que hoje vivem nas sedes de seus municípios, em processos que podem influenciar a mudança de vida de suas comunidades, municípios e territórios, apresentando, através de suas vozes, as preocupações que vêm lhes afetando de modo direto e, também, numa dimensão mais ampla. É a partir da afirmação das múltiplas identidades, da expressão de suas capacidades de análise e de propostas para enfrentamento das dificuldades vivenciadas e da interlocução intergeracional que estes e estas adolescentes e jovens suplantam a condição de vulnerabilidade na qual estão historicamente inseridas e inseridos e mostram suas potencialidades, contribuindo para a desconstrução de estigmas limitantes ao seu desenvolvimento e apresentando consciência e reinvindicações de seus direitos e de seus ambientes de pertencimento - em uma clara demonstração de empatia, solidariedade e consciência cidadã.

Palavras-chave: Covid-19, participação, infâncias e juventudes.

\section{Participe: una voz fuerte - Adolescentes y jóvenes sujetos a cambios en sus realidades en el Brasil profundo}

Resumen: Los jóvenes campesinos del Nordeste brasileño tienen múltiples identidades y deseos. No basta con referirse a ellos por su pertenencia territorial o solo por razones de género o étnico-raciales. Las deconstrucciones de estos imaginarios, que también compartimentan las

\footnotetext{
${ }^{1}$ Assistente Social, Mestra em Gestão Social e Desenvolvimento Territorial pela Universidade Federal da Bahia - UFBA e Coordenadora Nacional de Terre des Hommes Suisse, Suiça. Email: I.pinto@terredeshommessuisse.ch. ORCID: https://orcid.org/0000-0003-1979-9361.
} 
Dossiê | Participar: verbo em voz altiva - Adolescentes e jovens sujeitos de mudança das suas realidades no Brasil profundo (PINTO, Luciana)

luchas sociales y refuerzan estereotipos, son movimientos cotidianos hechos a partir de los más diversos mecanismos. A partir de la experiencia aquí presentada, del escenario pandémico Covid-19, el hilo conductor de esta reflexión es la dimensión de la participación de los adolescentes y jóvenes - niños, niñas, negros, campesinos - estudiantes, y que hoy viven en la sede de su municipios, en procesos que pueden incidir en el cambio de vida de sus comunidades, municipios y territorios, presentando, a través de sus voces, las inquietudes que les han venido afectando directamente $y$, también, en una dimensión más amplia. Es desde la afirmación de múltiples identidades, desde la expresión de sus capacidades analíticas y desde las propuestas para afrontar las dificultades vividas y el diálogo intergeneracional que estos y estos adolescentes y jóvenes superan la condición de vulnerabilidad en la que históricamente se encuentran insertados e insertados. mostrar sus potencialidades, contribuyendo a la deconstrucción de estigmas que limitan su desarrollo y presentando conciencia y reclamo de sus derechos y sus entornos de pertenencia, en una clara demostración de empatía, solidaridad y conciencia ciudadana.

Palabras-clave: Covid-19, participación, infancia y juventud.

\section{Participate: a loud voice - Adolescents and young people subject to change in their realities in deep Brazil}

Abstract: Youths from the northeastern Brazilian countryside have multiple identities and desires. It is not enough to refer to them based on their territorial belonging, or only by gender or racial ethnicity. Deconstructions of these imaginary, which also compartmentalize social struggles, and reinforce stereotypes, are everyday movements made from the most diverse mechanisms. From the experience presented here, considering the scenario of the Covid-19 pandemic, the guiding thread for this reflection is the dimension of the participation of adolescents and young people, boys, girls, blacks, people from the countryside and who today live in the headquarters of their municipalities, students, in processes that can influence the change of life in their communities, municipalities and territories, presenting through their voices the concerns that have been affecting them directly and also in a broader dimension. It is from the affirmation of multiple identities, from the expression of their analytical capacities and from proposals to face the difficulties experienced, from intergenerational dialogue, that these adolescents and young people surpass the condition of vulnerability to which they are historically inserted, and show their potential, despite these vulnerabilities, contributing to the deconstruction of stigmas limiting their development, and presenting awareness and claims of their rights and their environments of belonging, in a clear demonstration of empathy, solidarity and citizen awareness.

Keywords: Covid-19, participation, childhood and youth.

\section{Introdução}

O artigo que aqui apresentamos é um convite a olhar para a atuação das juventudes rurais no contexto da pandemia, a partir de sua identidade geracional, mas sem perder de vista as afirmações de pertencimento territorial, étnico-racial e de gênero. Trata-se de uma reflexão que parte da vivência empírica oportunizada por nossa prática na coordenação do escritório de Terre des Hommes Suisse no Brasil. 
Dossiê | Participar: verbo em voz altiva - Adolescentes e jovens sujeitos de mudança das suas realidades no Brasil profundo (PINTO, Luciana)

Terre des Hommes Suisse é uma organização da cooperação internacional suíça fundada há 60 anos - com sede em Genebra e escritório no Brasil em Salvador (BA) -, que atua em 10 países da África, Ásia, América Latina e há mais de 30 anos no Brasil, operando em prol dos direitos de crianças, adolescentes e jovens, mais especificamente à luz da proteção contra violências, direito à educação e direito à participação.

Como pano de fundo, traremos referências do semiárido baiano e da Chapada Diamantina, incluindo também reflexões de adolescentes e jovens dos estados de Pernambuco e Paraíba no contexto da pandemia da Covid-19, que assola o Brasil e o mundo e impacta a sociedade de distintas maneiras, de acordo com aspectos de geração, gênero, raça, etnia, classe e território.

Para adolescentes e jovens a responsabilidade por tentar cumprir e disseminar medidas de biossegurança dialoga com um convite à reinvenção da atuação por seus direitos e os de suas comunidades e territórios - frequentemente, atitudes que se mesclam com a reinvenção da própria vida em seus sentidos objetivos e subjetivos.

Como a participação da população infanto-juvenil pode, em um contexto tão difícil e adverso, influenciar para a melhoria da qualidade de vida das populações do campo e de seus territórios e comunidades? Como pode ser assegurada como direito? Em que medida é possível exercer protagonismo diante do paralisante terror provocado pelas mais se 170 mil mortes registradas pela Covid-19 em 09 meses $^{2}$, e mais de cinco milhões de casos?

É importante entender, aqui, que, de acordo com o que referencia Alejandro Cussianovich, o protagonismo não é apenas um conceito, mas algo que detém caráter político, social, cultural, ético, espiritual, e que, portanto, reclama uma pedagogia e convida a repropor o 'status' social de crianças, adolescentes, jovens e adultos sobre seus papéis na sociedade local e no conceito dos povos, em diálogos com outras identidades.

Dito isto, a experiência que fundamenta este artigo foi a pesquisa que culminou no Relatório "Vozes para a Mudança: Informe - Covid-19", elaborado entre março e maio de 2020 e publicado em junho de 2020. O relatório foi construído envolvendo 20 adolescentes e jovens de territórios rurais nos estados da Bahia, Pernambuco, Paraíba

\footnotetext{
${ }^{2}$ Até a elaboração deste artigo
} 
Dossiê | Participar: verbo em voz altiva - Adolescentes e jovens sujeitos de mudança das suas realidades no Brasil profundo (PINTO, Luciana)

(no Nordeste brasileiro), a partir de uma prática de pesquisa-ação, entendida como uma forma de investigar a realidade baseada em uma autorreflexão coletiva, em uma perspectiva colaborativa com os/as integrantes deste processo, que também bebe em fontes da Educomunicação - assegurando a horizontalidade entre pares como aspecto potencializador de narrativas.

A proposta buscou entender como adolescentes e jovens entre 16 e 28 anos, negras e negros ${ }^{3}$, que ocupam lugares e papéis de lideranças em suas comunidades ou municípios, percebiam as manifestações e as dificuldades da pandemia em seus ambientes, como observaram as medidas de enfrentamento, o que têm feito e com quais propostas gostariam de contribuir para minimizar os sofrimentos das populações mais vulneráveis, especialmente das áreas rurais de seus municípios.

Nesse sentido, nossa intervenção e interação com estas juventudes pretende construir pontes, entendendo-nos, institucionalmente, como "ferramentas" para que elas possam - por meio de práticas participativas - atuar no contexto da afirmação das suas identidades, fortalecimento da autonomia, construção, revisão e desenvolvimento de seus projetos de vida individuais e coletivos, influenciando nas transformações da realidade onde estão inscritas.

\section{O porquê da iniciativa no contexto da pandemia}

O quadro vivenciado pelo Brasil no contexto da pandemia da Covid-19 é, desde o seu princípio, devastador, e já traz consequências que vão além da saúde pública e da crise sanitária instaurada. Os reflexos estão presentes na intensificação e no surgimento de novas manifestações da questão social - dentre elas, o aumento agressivo dos índices de desemprego, os frágeis auxílios emergenciais estatais ao sistema de Saúde e aos mais indefesos, o crescimento das violências, especialmente a doméstica -, aspectos que são agravados pela estratégia negacionista adotada pelo governo brasileiro, que negligencia diretrizes claras ao enfrentamento da pandemia, buscando favorecer abertamente 0 lucro em detrimento da vida.

\footnotetext{
${ }^{3}$ Não se tratou de uma opção estratégica que apenas adolescentes e jovens negras e negros participassem da pesquisa e da construção do relatório. Por outro lado, todas e todos afirmaram esta identidade.
} 
Dossiê | Participar: verbo em voz altiva - Adolescentes e jovens sujeitos de mudança das suas realidades no Brasil profundo (PINTO, Luciana)

Embora crianças, adolescentes e jovens não sejam as mais afetadas pela letalidade da doença, elas são consideradas as vítimas invisíveis de suas consequências, especialmente no que concerne ao acesso a direitos básicos como educação, saúde, lazer, proteção contra violências, alimentação - sendo aspectos que são afetados tanto forma direta quanto a partir do impacto nas condições de vida de suas famílias, no que concerne à geração de renda, assistência social, etc.

O reconhecimento do impacto da pandemia na vida de milhares de crianças e adolescentes no Brasil e no mundo nos convida, institucionalmente, a disponibilizar aportes e recursos para desenvolver escuta e interação com as juventudes, de modo a permitir o fortalecimento de suas vozes e o planejamento conjunto de ações de apoio ao enfrentamento das consequências da pandemia em seus territórios.

Os resultados da pesquisa - além do relatório Vozes para a Mudança - se converteram no projeto que veio sendo desenvolvido durante todo o ano de 2020 , com apoio de organizações parceiras de Terre des Hommes Suisse e da Embaixada da Suíça no Brasil e direcionado a ações que comunicaram a prevenção e debateram com populações camponesas a sua realidade no contexto da pandemia.

No entanto, as dimensões deste artigo não alcançarão retratar os resultados da intervenção, que encontra-se em fase de conclusão e análise. Por esse motivo, optamos por nos concentrar nos resultados da pesquisa e na sua culminância, com a construção do relatório Vozes para a Mudança enquanto instrumento que garanta análise da realidade a partir das próprias narrativas de adolescentes e jovens, considerando perfil, problemáticas identificadas e propostas refletidas como parte da sociedade civil - onde intervêm, não enquanto um exercício pela cidadania do futuro, mas como parte do exercício de sua condição de sujeitos de direitos e de afirmação de seu lugar de fala. Para Djamila Ribeiro, pensar lugar de fala, implica "romper com o silêncio instituído para quem foi subalternizado, um movimento no sentido de romper com a hierarquia, muito bem classificada por Derrida como violenta" (RIBEIRO, 2017, p. 89).

A referência a este conceito é importante, aqui, por se conectar com dois outros aspectos relevantes que tratamos durante a pesquisa e que nos acompanham nas estratégias de intervenção, quais sejam: a adoção de metodologias geradoras de oportunidades para que adolescentes e jovens afirmem suas múltiplas identidades e a 
Dossiê | Participar: verbo em voz altiva - Adolescentes e jovens sujeitos de mudança das suas realidades no Brasil profundo (PINTO, Luciana)

dimensão da diversidade como ponto de partida determinante a uma participação de qualidade.

\section{Os objetivos da pesquisa e do relatório e seus percursos metodológicos}

O processo de pesquisa que desencadeou a construção do relatório Vozes para a Mudança - Informe Covid-19 teve, entre seus objetivos, evidenciar a situação dos direitos das crianças, adolescentes e jovens e seu impacto no contexto da Covid-19 no Brasil, com especial atenção às regiões semiáridas, no Nordeste do país, a partir do olhar de adolescentes e jovens lideranças; disseminar as necessidades e preocupações das juventudes quanto ao contexto da crise de Saúde causada pela pandemia da Covid-19; levantar elementos para planejar ações de intervenção durante o ano de 2020 pela Terre des Hommes Suisse, com base nas realidades analisadas, habilidades e condições disponíveis para contribuir com respostas que minimizem os impactos da pandemia e suas consequências nos territórios onde atua.

Construímos coletivamente com os/as adolescentes e jovens diversos pontos sobre os quais os instrumentais deveriam se debruçar. A partir daí, ouvimos 20 adolescentes e jovens lideranças em seus territórios e que se afirmam como negras e negros nas regiões do semiárido (territórios do Sisal, Sertão do São Francisco, Bacia do Jacuípe e Senhor do Bonfim) e da Chapada Diamantina (no estado da Bahia), mas também garantindo representações do agreste pernambucano e do sermiárido paraibano.

A identificação das e dos participantes teve por base seu vínculo com organizações parceiras apoiadas pela Terre des Hommes Suisse no Brasil de modo formal e mesmo organizações que estão no lugar de aliadas estratégicas ${ }^{4}$, tendo privilegiado o critério da acessibilidade e voluntariedade dos e das participantes, a partir de um contato direto com eles e elas, via WhatsApp e telefone.

A pesquisa se deu através de dois processos complementares: uma investigação preliminar, através da aplicação de um formulário eletrônico, em caráter de entrevista

\footnotetext{
${ }^{4}$ Chamamos de organizações parceiras locais aquelas que têm um vínculo sistemático de colaboração técnica, política e financeira com Terre des Hommes Suisse, e de aliadas estratégicas entidades e movimentos sociais que interagem de forma pontual ou não formal para a concretização de objetivos mútuos em suas práticas.
} 
Dossiê | Participar: verbo em voz altiva - Adolescentes e jovens sujeitos de mudança das suas realidades no Brasil profundo (PINTO, Luciana)

semiaberta, e na sequência, a realização de entrevistas em profundidade, com um grupo menor dentro dos 20 participantes inicialmente contactados. Ao total, aplicamos 20 formulários e realizamos sete entrevistas aprofundadas.

Assim, começamos a reconhecer, a partir das narrativas de adolescentes e jovens, as dificuldades vivenciadas por conta da pandemia, como também experimentamos várias dessas dificuldades na realização da pesquisa. Notadamente, aqui destacamos já as manifestações da exclusão digital, que no contexto da pandemia ganhou evidência pela impossibilidade de interlocução presencial.

A pesquisa conheceu o perfil destes e destas adolescentes e jovens, verificou suas problemáticas, confirmou iniciativas já realizadas em seus territórios pelo poder público ou pela sociedade civil que eram de seu conhecimento, apontou interesses em mobilizar esforços para ações conjuntas que minimizassem certas problemáticas, habilidades, condições de acesso à tecnologia, mecanismos de acesso à informação e mudanças nos seus cotidianos que poderiam afetar sua participação e limitações impostas pelo cenário. Além disso, os/as jovens apontaram em seus depoimentos temas que consideraram relevantes, públicos com quem gostariam de interagir e com quais ferramentas comunicacionais - inclusive fortalecendo iniciativas que já estão em curso e quais apoios eram necessários.

A partir dos resultados foi possível - em articulação com quatro organizações parceiras da Terre des Hommes Suisse no Brasil e com o coletivo de jovens - planejar uma intervenção que coubesse nas suas condições de participação e que estivessem conjugadas com as suas realidades.

\section{Quem são essas/esses adolescentes e jovens?}

Como mencionado anteriormente, 20 adolescentes e jovens ${ }^{5}$ entre 17 e 28 anos responderam à pesquisa no formulário eletrônico. Destas e destes, sete ${ }^{6}$ se disponibilizaram a participar da entrevista aprofundada7. No tocante à identidade étnico-racial todas as pessoas se declararam negras. Sobre a escolaridade, metade já

\footnotetext{
512 femininos e oito masculinos.

${ }^{6}$ Três masculinos e quatro femininos.

${ }^{7} \mathrm{Na}$ entrevista aberta desse grupo, em termos de gênero, uma pessoa se declarou bissexual.
} 
Dossiê | Participar: verbo em voz altiva - Adolescentes e jovens sujeitos de mudança das suas realidades no Brasil profundo (PINTO, Luciana)

acessou a universidade, mesmo que não a estejam cursando por necessidades de interrupção - desse total, $25 \%$ já a concluíram. Os outros terminaram o ensino fundamental e um está cursando o nível médio.

Todas e todos vêm de pequenas e médias cidades no interior de três estados do Nordeste brasileiro envolvidos na pesquisa (Bahia, Paraíba e Pernambuco). Embora haja representantes de áreas urbanas, sem exceção, todos têm vínculos com as áreas rurais, incluindo-se também territórios quilombolas, mais especificamente na região da Chapada Diamantina, na Bahia, e comunidades de "fundo de pasto", no semiárido baiano ${ }^{8}$. São filhas e filhos de famílias de agricultores e quilombolas que, por vezes, migraram para os centros dos municípios para prosseguir com os estudos ou expandir as oportunidades de trabalho para além da produção agrícola ${ }^{9}$.

Em termos de participação, além de interagirem com iniciativas promovidas pela Terre des Hommes Suisse e pelas ONGs parceiras, todas as pessoas que participaram da pesquisa mencionaram integrar outros espaços de participação, em níveis diferentes de interlocução, tais como associações comunitárias, grupos de jovens, coletivos artísticos, grupos das igrejas, Pastoral da Juventude, sindicatos, movimentos sociais do campo, coletivos antirracistas, conselhos de políticas públicas, dentre outros.

No acesso à infraestrutura básica a maioria tem energia elétrica disponível, e apenas uma pessoa mencionou interrupção frequente no fornecimento. Quanto à internet, a "banda longa" é garantida para a maioria, mas com diferentes graus de estabilidade na rede/sinal. Todos possuem equipamentos a partir dos quais se pode produzir e transmitir conteúdos, tais como computadores ou smartphones, sejam estes equipamentos próprios ou disponibilizados pelas organizações ou coletivos dos quais participam. Além disso, foram mencionados, também, alguns acessórios, como aparelhos auditivos, câmaras fotográficas, filmadoras e gravadores de voz - estes foram

\footnotetext{
${ }^{8}$ Comunidades de fundo de pasto são espaços típicos do semiárido baiano que se caracterizam pela posse e uso comunitário da terra e dos seus recursos, com especial destaque para a criação de animais, especialmente a caprinocultura, em um formato de criação livre, onde suas criações são reconhecidas por marcas feitas pelos seus donos. Tal modelo de criação facilita o acesso dos animais à água e à comida, principalmente nos períodos de estiagem severa, além de ser um exemplo de adaptação e convivência com o clima semiárido da região.

${ }^{9}$ Dentre as organizações envolvendo jovens estão: Escola Agrícola Família de Sertão (EFASE), Movimento de Organização Comunidade (MOC); Serviço Consultivo às Organizações Populares Rurais (SASOP); Associação de Grãos de Luz (GdL); AS-PTA Agricultura Familiar e Agroecologia.
} 
Dossiê | Participar: verbo em voz altiva - Adolescentes e jovens sujeitos de mudança das suas realidades no Brasil profundo (PINTO, Luciana)

citados, muitas vezes, pelos que estudam ou estão envolvidos em alguma atividade de trabalho voltada para a Comunicação.

Já no âmbito do acesso à informação as redes sociais são uma forma fácil de acesso, destacando o Youtube, o Facebook, o Instagram ou chats de conversas e mensagens como o WhatsApp. Quando se trata do acesso a informações sobre a pandemia da Covid-19, muitos mencionaram portais conjuntos, jornais, sites de ONGs e de movimentos sociais de sua confiança. Não houve menções a veículos da mídia comercial e das grandes corporações, o que nos leva a inferir certo posicionamento crítico em relação à direção ideológica de certos veículos.

Estes aspectos básicos de compreensão da realidade destes e destas adolescentes e jovens nos permitem perceber que, apesar da condição de vulnerabilidade a que estão expostos, em termos de acesso a muitos direitos, os esforços pessoais e familiares empreendidos, associados ao apoio institucional de ONGs locais e movimentos sociais - que lhes impulsionaram para lugares de lideranças juvenis conquistados em seus territórios -, Ihes apresentam nesta pesquisa como estando em uma condição diferenciada da maioria da juventude brasileira do campo, especialmente no contexto da pandemia. Nesse sentido, é importante mencionar que não há aqui uma pretenção de generalizar este perfil ou estendê-lo a uma população adolescente e jovem do país, ou mesmo de municípios do interior nordestino, o que careceria de um outro nível de investigação que não converge com o que foi pretendido nesta iniciativa.

\section{Com a palavra, adolescentes e jovens: o impacto da pandemia sobre seus direitos}

13,5 milhões de pessoas no Brasil estão em situação de extrema pobreza. Tal situação atravessa outras condições de vulnerabilidade, como aquelas em que estão inseridas mulheres, meninas, idosos, negras e negros, deficientes, doentes ou viciados, residentes em moradia precária, pessoas com limitações de renda e expostas à violência. Essa situação tem um impacto ainda maior durante a pandemia, onde as pessoas equilibram sua saúde com sua sustentabilidade econômica.

Enquanto questionam a quantidade de tempo, as crianças, adolescentes e jovens passarão pela pandemia fechadas em suas casas para se protegerem do contágio de Covid-19. A pesquisa mostrou outras preocupações por parte das juventudes, tais como: 
Dossiê | Participar: verbo em voz altiva - Adolescentes e jovens sujeitos de mudança das suas realidades no Brasil profundo (PINTO, Luciana)

o que acontece com a população que não está cumprindo com o isolamento e que está colocando em maior risco suas vidas e saúde? Elas recebem informações suficientes e de qualidade que as permitam se proteger? Como deve se portar quem sobrevive a partir da produção e comercialização agrícola e pecuária? Existem orientações específicas para esta população? Como apoiar adolescentes e jovens em sofrimento mental por consequência do confinamento? Quais as rotas de apoio para meninos e meninas vitimas de violência doméstica, que muito cedo passou a dar sinais de intensificação e de redução das possibilidades de denúncia?

Com mais perguntas que respostas, as angústias apresentadas pela juventude tinham um ponto de partida: seu direito de sonhar. $\mathrm{O}$ impacto em seus projetos de vida pessoais revelava que desejos recém alcançados, como ingressar em uma universidade ou em um curso técnico, eram interrompidos pela pandemia, sem data marcada para serem retomados. Tais realizações também foram frequentemente ameaçadas por circunstâncias de vida que lhes obrigavam a buscar - além de outros sentidos para seus cotidianos - formas de garantir e apoiar a subsistência de sua família, já que havia uma baixa na renda familiar, fosse pela dificuldade em escoar produção agrícola, fosse pela redução de postos de trabalho e o desemprego massivo que rapidamente começou a dar seus sinais no cenário inicial da pandemia.

A economia, que vai afetar adolescentes e jovens, sejam menores ou maiores de 18 anos, e eles já estavam conseguindo seu primeiro emprego, e agora com a queda da economia, vai ficar ainda mais difícil, porque já não era fácil. Então a pandemia vai afetar muito, já está afetando o presente e vai afetar a vida de crianças e adolescentes no futuro (Nathyele Lima, Conceição do Coité, BA).

O risco da pandemia está afetando muito o sistema emocional das pessoas. Tem sido muito chocante, porque é uma mudança total de rotina. As crianças estavam acostumadas a ir à escola, costumavam brincar na rua, tendo contato com outras pessoas. Os jovens também estavam na dinâmica escolar e em contato com outras pessoas, e isso não está acontecendo. Digo isso da minha realidade lá dentro (Sidinéia Camilo, Remígio, PB).

No âmbito do direito à educação, de acordo com o Censo Escolar 2019, o Brasil tem cerca de 39 milhões de crianças e adolescentes matriculados na rede pública de educação básica. Destes, 8,9 milhões estão matriculados em creches e pré-escolas, 26,9 milhões no ensino fundamental e 7,5 milhões no ensino médio. Em 2019, 47,9 milhões 
Dossiê | Participar: verbo em voz altiva - Adolescentes e jovens sujeitos de mudança das suas realidades no Brasil profundo (PINTO, Luciana)

de matrículas foram registradas nas 180,6 mil escolas de educação básica do país, sendo que a rede municipal é responsável por aproximadamente dois terços das escolas (60\%).

O impacto na educação das crianças é evidente. Meninos e meninas, adolescentes e jovens, especialmente as/os mais vulnerabilizados, se encontram em desvantagem nas condições adequadas para o acesso à dinâmica escolar. Isso se dá por falta de tempo, por falta de condições de seus cuidadores, devido a dificuldades no conhecimento de ferramentas ou excesso de trabalho - o que, por outro lado, também Ihes deixam muito mais expostos à perda total do direito à educação, por riscos de evasão ou de impossibilidade de um desempenho escolar adequado, como também sujeitos à insegurança alimentar e a riscos de violência e de desesperança.

Nossos pais não nos incentivam a fazer atividades de aprendizagem ligadas à educação. Crianças, adolescentes e jovens precisam de estímulo. Além disso, vem a questão da relação em casa. Percebemos que muitas famílias não têm uma relação de diálogo com seus filhos, de buscar saber sobre seus sentimentos, como eles são. Então, se as crianças estão em casa, ficam no celular ou na televisão, onde acessam muitas informações que não são adequadas para elas. A internet é uma terra que ninguém domina, então eles podem buscar mil informações e encontrar conteúdo que não contribuem para o seu desenvolvimento. Assim, a pandemia tem um impacto muito grande na educação, no exercício desse direito. Porque a educação ao vivo não é mais da maneira que deveria, imagine com as crianças dentro de casa (Camila Santos, Itiúba, BA).

Enquanto meninas e meninos são esperados para acessar aulas virtuais, esse ideal é impossível devido à falta de recursos, com a ausência de capacidade econômica de Ihes fornecer as ferramentas tecnológicas e a falta do Estado para Ihes garantir o direito à educação de forma eficaz e abrangente - problemática esta que dialoga com dois temas estruturantes: a frágil internalização social da comunicação como um direito humano e a exclusão digital latente em nosso país.

As alternativas para que o direito à educação se concretize durante a pandemia têm se mostrado deficiências estruturais. A falta de uma política pública federal desorienta estados e municípios quanto a caminhos minimamente viáveis, e as experimentações metológicas consomem tempo e exigem habilidades que nem sempre são parte do cotidiano de profissionais de educação para ensino fundamental e médio e menos ainda em cidades de pequeno porte. Posto isto, implica dizer que estes sujeitos 
Dossiê | Participar: verbo em voz altiva - Adolescentes e jovens sujeitos de mudança das suas realidades no Brasil profundo (PINTO, Luciana)

vêm lançando mão de compromisso pessoal, disponibilidade de tempo e recursos e contando com pouquíssimos apoios para driblar os desafios de um cenário tão adverso.

Em uma relação direta com o direito à educação, adolescentes e jovens participantes da pesquisa refletiram sobre a dimensão da segurança alimentar e da garantia do direito à alimentação como parte de suas preocupações. Segundo o Censo Escolar 2019, o Brasil possui quase 39 milhões de crianças e adolescentes matriculados na rede pública de educação básica. Dessas, 8,9 milhões estão matriculadas em creches e pré-escolas; 26,9 milhões no ensino fundamental; e 7,5 milhões no ensino médio. No ano de 2019 foram_registradas 47,9 milhões de matrículas nas 180,6 mil escolas de educação básica no Brasil. Desse total, a rede municipal é responsável por aproximadamente dois terços das escolas (60\%). Levando-se em consideração esses aspectos, tem-se ainda o fato de que, para muitas dessas crianças e adolescentes, a merenda escolar é a única refeição durante todo o dia.

Para muitas famílias, mandar crianças para a escola é um sacrifício, pois elas não têm renda fixa, então quando seus filhos vão para a escola, isso também reduz o custo da alimentação familiar, já que as crianças se alimentam na escola. O que acontece hoje é que o confinamento aumenta o consumo de alimentos em casa, e as famílias não têm uma reserva financeira para garantir isso. A luta é para que, durante o tempo da pandemia de coronavírus, a alimentação escolar seja fornecida às famílias. Em certos municípios isso já é o assunto, mas em muitos, não (Camila Vitória, Riachão de Jacuípe, BA). ${ }^{10}$

Outra preocupação apresentada nos resultados da pesquisa foram as diversas manifestações de violências contra crianças, adolescentes e jovens - e, nesse sentido, agravadas pelo contexto da pandemia e pela contradição entre o aumento de casos e as dificuldades para efetuar denúncias e acessar uma rede de proteção. Tal situação, em alguns momentos, ajudou a maquiar dados de registros oficiais, já que muitas vitimas, isoladas, sequer conseguiam efetuar a denúncia de casos. Para as e os jovens escutados, a violência de gênero contra mulheres jovens e adultas é também um fenômeno que

10 A fala da adolescente Camila Vitória, mencionada acima, refere-se à lei 786/2020 (Lei Federal 13.987/20), garantindo a alimentação de qualidade às crianças (da educação básica) afastadas das escolas públicas, dado o cenário de insegurança alimentar em que estes e estas estudantes se encontram, a partir da suspensão das aulas na rede pública de ensino. O PL 786/2020, também chamado de PL da Merenda, aprovado pelo Senado no dia 30/03/2020 e pelo Presidente da República no dia 07/04 deste ano, ganhou força de lei e execução em todos os municípios brasileiros. 
Dossiê | Participar: verbo em voz altiva - Adolescentes e jovens sujeitos de mudança das suas realidades no Brasil profundo (PINTO, Luciana)

passa pela violência infantil, pela afirmação do machismo - culturalmente mais exacerbado em ambientes rurais, que desencadeia formas cotidianas de violências subjetivas e simbólicas junto a meninos e meninas, que precedem a violência física e são constantemente naturalizadas na nossa sociedade.

Existe o problema de que, para adolescentes e jovens que são abusados sexualmente, eles são mais propensos a sofrer ainda mais nesse período quando está em casa. O responsável é a pessoa que é violenta. Já vi até alguns estudos de São Paulo, e um também no meu estado, a Paraíba, que foi publicado pelo jornal Brasil de Fato - PB, no qual mostrou dados sobre o aumento da violência doméstica. Eu realmente acredito que essa violência doméstica também vem como um feminicídio para as mulheres, e vem como violência e abuso sexual para crianças e adolescentes. Eu falo mais sobre garotas, mas não é que os meninos não sofram. Eles também sofrem, mas são as garotas que mais sofrerão... Estou preocupado com a questão da segurança. Porque, obviamente, ainda temos um cenário de aumento de denúncias de violência contra a mulher, que também se reflete em crianças e adolescentes, que geralmente são atendidos pelo conselho tutelar, ou pelo centro de referência de arte e cultura do município, e lá, como esses órgãos não estão funcionando, porque não há como trabalhar no campo, as crianças estão em uma situação de vulnerabilidade ainda maior (Mônica Lourenço, Campina Grande, PB).

As problemáticas apresentadas aqui, como sendo as principais enfocadas nas narrativas de adolescentes e jovens que participaram da pesquisa, não são um fim em si mesmo. O processo desenvolvido permitiu uma articulação entre as preocupações apresentadas, convertendo-as em temáticas para o planejamento de uma ação, na perspectiva do protagonismo infanto-juvenil, conciliada com as condições de intervenção, em termos de tempo, interesse, habilidades, contextos destes e destas adolescentes e jovens, bem como as capacidades de apoio ao fortalecimento técnico, metodológico e material que a Terre des Hommes Suisse e seus parceiros podem viabilizar para o desenvolvimento de uma iniciativa voltada à sua participação efetiva no desenvolvimento da sociedade, a partir de seus territórios.

\section{Há de ser uma voz de resistência - adolescentes e jovens como sujeitos de mudança}

Adolescentes e jovens estão muito conscientes dos limites impostos a eles pelo isolamento social, mas, para eles, vale a máxima: "ficar em casa não é calar a boca". Ao mesmo tempo, eles estão cientes de formas de apoiar as populações e não querem 
Dossiê | Participar: verbo em voz altiva - Adolescentes e jovens sujeitos de mudança das suas realidades no Brasil profundo (PINTO, Luciana)

apenas contribuir entre pares, mas também influenciar mudanças em suas comunidades, municípios e territórios, fornecendo informações para outros grupos geracionais, seja no contexto da informação de prevenção, seja em termos de acesso a políticas públicas - sempre identificando a melhor maneira de fazer com que informações seguras e confiáveis cheguem às populações, investindo também contra o vírus da desinformação.

A voz das crianças, adolescentes e jovens demonstrou que pode transcender o espaço privado para se amplificar por meio das mídias sociais, tomando o exemplo do bom cumprimento das disposições governamentais para toda a população, difundindo medidas de prevenção, mas também tornando visíveis as necessidades da comunidade e de todos esses direitos que foram cortados e dificultados. Para manter suas vozes não truncadas é necessário acesso à conectividade permanente, energia elétrica ou alternativa, equipamentos, tecnologia e serviços de telecomunicações.

Sua preocupação é constante, por isso promovem o autocuidado, a solidariedade para com os mais vulneráveis e conscientizam sobre a boa saúde e os hábitos alimentares, considerando os saberes e experiências que vêm de suas próprias comunidades, enfrentando a violência e o medo com coragem, bem como a participação para exercer a cidadania ativa, exigindo os direitos que lhes pertencem e apostando em um futuro melhor, onde eles estão como resistência.

Agora é mais do que necessário exercer nosso papel como cidadão, porque há muitas notícias falsas e pessoas desinformadas e temos que ajudá-las de alguma forma (lara Moreira).

Levar a informação para quem não pode acessá-la, quem não tem redes sociais, por exemplo. No meu bairro há alguns anciãos que vivem sozinhos, e que têm alguma abordagem para eles, aqueles que eu não tentei criar. Eu já fiz um mercado para dois idosos, amanhã eu vou fazer isso para alguém que me pediu. Então é isso, ajuda no que for preciso, especialmente para aqueles que não têm acesso à informação, espalhando a palavra sobre o que está acontecendo, chamando a atenção para o número de mortes, para que todos possam ter um vislumbre do que está acontecendo em nosso país, em nosso estado e em nossas vidas (Nathyele Lima, Conceição do Coité, BA).

Eles usam todos os seus recursos para compartilhar seus conhecimentos com sua comunidade, preocupados em manter a estabilidade emocional, humor, sensibilidade e 
Dossiê | Participar: verbo em voz altiva - Adolescentes e jovens sujeitos de mudança das suas realidades no Brasil profundo (PINTO, Luciana)

solidariedade, bem como empatia e resiliência. Reinventam-se continuamente, passando por um cenário totalmente sem precedentes para elas e para eles.

Devemos enfrentar este momento juntos. Crianças, adolescentes e jovens são criativos e podem ajudar a comunidade sem sair de casa (Breno Santiago, Retirolândia, BA).

Nosso papel, enquanto Terre des Hommes Suisse, é criar condições para que a voz de crianças, adolescentes e jovens vá além, articulando suas leituras da realidade, demandas, problemas e propostas com ferramentas e contribuições para que suas ações, enquanto agentes de mudança, de suas vidas e de seus ambientes, possam ser concretadas e afirmadas cada vez mais fortemente.

Com essa pesquisa qualitativa é possível ver as condições que crianças, adolescentes e jovens têm para agir, tanto a partir das condições externas (operacionais e práticas) quanto ao que toca seu grau de consciência, capacidade de empatia, desejo, interesse e adequação da realidade.

Dessa forma, este documento não é o fim, mas o início de um processo, no qual estamos conscientes de nossa responsabilidade e do nosso papel de contribuir para a realização, não só do direito à participação, mas de promover caminhos de resistência e de fortalecer as lutas por direitos e mudanças de realidades de cada pessoa, suas famílias, comunidades e seu meio ambiente.

\section{À guisa de conclusão}

Dentre os resultados para os quais a pesquisa apontou, confirmamos a capacidade propositiva e transformadora das juventudes, tendo a afirmação de identidades territoriais, de gênero e étnico-raciais como ponto de partida para processos de empoderamento e fortalecimento de autonomia e exercício de protagonismo. Em outra dimensão, a pesquisa permitiu, também, confirmar habilidades e competências postas a serviço das comunidades e do bem comum, e o reconhecimento da capacidade de influenciar suas realidades, buscando ocupar lugares de poder através de linguagens e narrativas para comunicar necessidades, propor alternativas de enfrentamento e desenvolver práticas que influenciem outras e outros 
Dossiê | Participar: verbo em voz altiva - Adolescentes e jovens sujeitos de mudança das suas realidades no Brasil profundo (PINTO, Luciana)

adolescentes e jovens e adultos - inclusive na busca por fortalecer os diálogos intergeracionais e reduzir práticas adultocentradas tão presentes em nossa sociedade.

Do ponto de vista do aspecto racial, o lugar da juventude negra em processos como estes foi tratado durante toda a pesquisa e também nas ações de intervenção que dela desencadearam, não do ponto de vista das denúncias sobre violações e violências sofridas pela população diuturnamente em nosso país. Em que pese a relevância de visibilizar este aspecto, optamos, em nossa estratégia, por chamar a atenção para as potências das populações negras, inclusive pelas particularidades concernentes a sua identidade étnico-racial, capacidades de realização e de transformação da realidade inclusive, também no âmbito do combate ao racismo, mas não somente por este aspecto. Reconhecemos que as condições de vida frequentemente adversas a que estão expostas e expostos são fortemente influenciadas pelo racismo estrutural que perpassa a sociedade e pelo qual negras e negros tentam atravessar em seus cotidianos.

A adolescência e a juventude são identidades geracionais e, portanto, transitórias, que não estão desarticuladas do seu contexto social, político e econômico. A vida das crianças e dos adolescentes acontece dentro das cidades. Elas moram numa rua, têm vizinhos, têm pais que têm acesso ou não às políticas públicas. Assim sendo, as políticas públicas têm essa função de regular nosso modo de estar com os outros, de construir equidades. Dito isso, nos perguntamos: que condições de acessibilidade estão sendo criadas para que crianças e adolescentes, na sua pluralidade, possam se aproximar, atuar e serem ouvidas na construção de políticas públicas destinadas a elas? Nossa sociedade é preconceituosa em relação às potencialidades de jovens e adolescentes. O estigma é ainda maior entre negros, indígenas, crianças e adolescentes com deficiência e moradores de comunidades populares e rurais.

Nessa escuta, ouvimos crianças e adolescentes sinalizarem que precisamos, enquanto instituições da sociedade civil, repensarmos nossas estratégias para construir, coletivamente, a partir de um diálogo intergeracional, nossa vida em comunidade. Tanto na pesquisa quanto no planejamento das intervenções subsequentes elas nos instigam a reconhecer e valorizar o processo, o tempo e a natural necessidade de maturação. E abandonar buscas incessantes por atalhos e respostas prontas.

No sentido da expressão dos desafios e limitações que a pandemia trouxe à vida de crianças, adolescentes e jovens, destacamos a manutenção da periodicidade dos 
Dossiê | Participar: verbo em voz altiva - Adolescentes e jovens sujeitos de mudança das suas realidades no Brasil profundo (PINTO, Luciana)

encontros formativos e sua realização de forma mais sistematizada; as dificuldades para mobilizar mais jovens na perspectiva de ampliar a força deste coletivo para além do grupo mais intensamente vinculado: e planejar a disseminação dos produtos de forma participativa. No tocante às dificuldades técnicas, mesmo com a oferta gratuita, por parte do projeto, de recarga de dados de celular e outras formas de conexão, isso não foi suficiente diante de um contexto de exclusão sistemática das juventudes rurais.

A dimensão da afirmação da identidade negra foi um elemento presente nos produtos de comunicação planejados a partir dos resultados da pesquisa, à medida que se buscou, também, criar conteúdo que levasse em conta dois aspectos importantes: insistir em chamar a atenção da opinião pública quanto às condições mais intensas de desigualdades às quais estão expostas essas populações, e, por outro lado, afirmar que, mesmo em condições adversas, existe uma potência a ser revelada, uma voz que não quer ser calada, e que utiliza destas oportunidades para afirmar-se social e publicamente, em dignidade, em capacidades e na reivindicação de seus direitos.

Nesse sentido, o projeto alcança - e, até ousaríamos dizer, que supera - seus objetivos quando permitiu que crianças e adolescentes, ao intensificarem ou apreenderem sobre a comunicação como uma ferramenta de participação, como um direito e uma estratégia para reivindicar e garantir outros direitos, reconhecem também, em ações como estas, a potência de suas vozes, enquanto agentes de transformação da realidade - não para quando se tornarem adultos, mas desde já, e a partir das visões de mundo que assimilam e formam a cada dia.

\section{Referências}

BRASIL. Lei Federal 8.069. Estatuto da Criança e do Adolescente. Brasília. DF. 1989.

BRASIL. Ministério da Educação/Instituto Nacional de Estudos e Pesquisas Educacionais Anísio Teixeira (INEP). Censo da Educação Básica/2019. Brasília/DF/2020. ORGANIZAÇÃO DAS NAÇÕES UNIDAS (ONU). Convenção Internacional dos Direitos das Crianças - CDC. 1989.

RIBEIRO, Djamila. O que é Lugar de Fala. Belo Horizonte: Letramento, 2017. 112 p. Feminismos Plurais.

SANTOS, Luciana F Pinto. Masculinidade Tóxica e cultura do cuidado. Salvador, novembro, 2020. (a autora). Artigo fruto da participação na Roda Juventudes Já, promovida pelo Fundo das Nações Unidas para as Populações - UNFPA. 
Dossiê | Participar: verbo em voz altiva - Adolescentes e jovens sujeitos de mudança das suas realidades no Brasil profundo (PINTO, Luciana)

SILVA, Alexandre Magno Tavares da. Protagonismo Juvenil, Pedagogia Social e o Pensamento Pedagógico Freireano: alguns desafios e perspectivas para a formação de educadores e educadoras sociais em projetos socioeducativos. Interritórios | Revista de Educação da Universidade Federal de Pernambuco, Caruaru, BRASIL | V.1 | N.1 [2015].

TERRE DES HOMMES SUISSE. Vozes Para a Mudança - Informe Covid-19. Salvador, junho, 2020.

TERRE DES HOMMES SUISSE, Voces Por el Cambio - Informe Covid 19 América Latina. Bogotá, maio, 2020.

TERRE DES HOMMES SUISSE, Relatório do projeto - Direitos em Tempos de Covid19: A voz de crianças e jovens. Salvador, novembro de 2020. Em parceria com a Embaixada da Suíça no Brasil.

www.vocesparaelcambio.org (Portal Vozes para a Mudança). 